University of Nebraska - Lincoln

DigitalCommons@University of Nebraska - Lincoln

Marketing Department Faculty Publications

Marketing Department (CBA)

$9-2009$

\title{
Consequences of customer powerlessness: Secondary control
}

Matthew Bunker

University of Northern lowa, matthew.bunker@uni.edu

A. Dwayne Ball

University of Nebraska - Lincoln, dball1@unl.edu

Follow this and additional works at: https://digitalcommons.unl.edu/marketingfacpub

Part of the Marketing Commons

Bunker, Matthew and Ball, A. Dwayne, "Consequences of customer powerlessness: Secondary control" (2009). Marketing Department Faculty Publications. 8.

https://digitalcommons.unl.edu/marketingfacpub/8

This Article is brought to you for free and open access by the Marketing Department (CBA) at DigitalCommons@University of Nebraska - Lincoln. It has been accepted for inclusion in Marketing Department Faculty Publications by an authorized administrator of DigitalCommons@University of Nebraska - Lincoln. 
Published in Journal of Consumer Behaviour 8 (Sept/Oct 2009), pp. 268-283; doi: 10.1002/cb.287

Copyright ( 2009 John Wiley \& Sons, Ltd. Used by permission.

http://www.interscience.wiley.com

\title{
Consequences of customer powerlessness: Secondary control
}

\author{
Matthew Bunker \\ Associate Professor of Marketing, University of Northern Iowa, 345 Curris Business Building, \\ Cedar Falls, IA 50614-0126, USA. Corresponding author: email matthew.bunker@uni.edu
}

\section{A. Dwayne Ball}

Associate Professor of Marketing, University of Nebraska-Lincoln, Lincoln, NE 68588, USA

\begin{abstract}
This research investigated the consequences of powerlessness when consumers experience service failure with a company that has high-exit barriers. The specific consequences investigated were three types of secondary control, which are grudge-holding, avoidance (predictive avoidance), and retaliation desire. These secondary control coping strategies highlight consumers' ability to control their personal behaviors and thoughts, even when they cannot completely control the outcomes of a situation. A qualitative study, followed by a scenario-based survey and structural equation model, suggest that the primary direct consequences of powerlessness in commercial relationships are grudgeholding and predictive avoidance, and that both predictive avoidance and a desire to retaliate are further consequences of grudge-holding. The results of this research underscore the importance of understanding the role of powerlessness and its consequences in consumer-firm relationships.
\end{abstract}

\section{Introduction}

Powerlessness is the feeling that events are out of one's control. The purpose of this paper is to delineate the consequences of customer powerlessness in service relationships. In particular, we are interested in the case in which the consumer feels trapped in a relationship with an opportunistic marketer. Such relationships occur: almost any consumer can tell of a relationship with a utility, government entity, telecommunications firm, etc., in which the customer believed he or she was taken advantage of or treated poorly but could not exit the relationship without incurring unacceptable cost.

Powerlessness is often a function of lack of choice or of unrecoverable service or product failure. For example, in some places, there is only one cable television company and prices are higher. People are aware that others with choice pay less but can do nothing about it if they want cable service. A customer who purchases a car expecting 32 miles per gallon on the highway but who gets only 25 despite a moderate driving style usually has no acceptable way to alter the situation. In that case, the customer still has a relationship with the pro- 
ducing firm (a service relationship) but feels powerless. The experience of at least occasional frustration with one's powerlessness is probably universal among customers; only the product or service context varies. We believe that customer responses to powerlessness, therefore, deserve attention.

We manipulate powerlessness in a customer relationship, measure consequences of powerlessness, and then propose and test the relationships among those consequences. We will show that the relationship consequences of powerlessness include secondary coping behaviors: grudge-holding, withdrawal from active participation in the relationship, and desire to retaliate. The importance of these coping behaviors lies in the eventual effects on the relationship. The customer-firm relationship is weakened, overt or covert retaliation may take place, and the introduction of alternatives in the market may provoke quick exit.

As examples, consider that prior to 1984 and the break-up of the national telephone monopoly of $\mathrm{AT} \& \mathrm{~T}$, there were frequent media jokes about the uncaring nature of the monopoly and the powerlessness of consumers (the comedienne Lily Tomlin performed the iconic AT\&T operator routine: "We don't care. We don't have to. We're the Phone Company"). When the market was opened up, new long-distance telecommunications companies quickly gained considerable share at the expense of AT\&T.

\section{Powerlessness}

The construct of consumer powerlessness is defined as an expectancy of an individual that her or his behavior cannot achieve desired outcomes (Seeman, 1959). Because of the context here (customerfirm relationships), we further refine the definition of powerlessness as the customer's belief that he or she is unable to influence the outcomes of a relationship with a firm. In other words, the firm holds a large majority of power in the relationship and the customer (in the extreme case) is trapped and open to exploitation. Such a feeling is uncomfortable for a customer and potentially threatening to his or her sense of agency, competence, and self-worth.
Powerlessness is similar to other constructs such as learned helplessness (Seligman, 1975) and lack of self-efficacy (Bandura, 1986), but there are also some important differences that exist between these constructs (Rucker and Galinsky, 2008). As mentioned earlier, powerlessness is defined as a person not having the ability to achieve desired outcomes, yet the feeling of powerlessness is context-specific (Rucker and Galinsky, 2008). For example, a customer may feel powerless when an airline flight is inexplicably delayed for several hours. Yet that same customer may also hold a high position as an executive at a large company and normally feels powerful.

Learned helplessness, on the other hand, occurs after multiple failures to control outcomes and has the potential to affect a person's belief in their ability to exert control in other, non-related situations. In other words, helplessness extends beyond the situation and influences how a person copes with other difficult situations (Mikulincer, 1994). For example, a person operating in the learned helplessness paradigm may not believe that complaining about late flights would result in a positive outcome, because complaining at work brought negative outcomes.

Self-efficacy is another construct that is closely related to power/powerlessness, and is a self-perception that one can accomplish a predetermined task (Bandura, 1986). Self- efficacy is a motivating force that enables people to persist in their efforts to complete that task despite facing challenges and failures (Yi and Gong, 2008). But if due to a delayed flight, a customer was stranded at a small regional airport that only a single airline services, no amount of self-efficacy would enable that person to fly from that airport sooner than the expected delayed time. Even if a person was typically high in self-efficacy beliefs for most tasks, she or he would still feel powerless due to this situation.

Understanding powerlessness in a marketing context is important because people who feel powerless in a relationship may approach that relationship with a great deal of vigilance concerning the more powerful others' benevolent or ma- 
levolent intentions (Fiske et al., 1996). As Keltner et al. (2003) point out, "Reduced power is associated with (a) negative affect; (b) attention to threat, punishment, others' interests, and those features of the self that are relevant to others goals..." In other words, powerlessness is not a state conducive to easy and comfortable relationships. Powerlessness in this context is very similar to the discussion of the effect of external conditions on vulnerability Baker et al. (2005). For example, powerlessness is not necessarily a constant variable, but is also associated with external variables such as customers feeling powerless because a service representative either refuses or does not have the ability to help them after a service failure occurs.

\section{Secondary control}

Coping with stressful situations can involve one or both of two coping strategies: primary control and secondary control (Rothbaum et al., 1982). Primary control is the use of active behaviors to alter a situation to one's liking. Secondary control is the use of active or passive behaviors to alter oneself rather than altering the situation. For example, when faced with a rude service employee, primary control would be remonstrating with the employee or her manager in order to obtain better service or an apology; secondary control would be to say nothing, but to content oneself with the observation that "everyone has bad days."

Control of outcomes is a major theme of life itself, at least in individualistic cultures; humans seek to control outcomes in their environments, hate to lose control of outcomes, and will experience powerful negative emotions when denied control (White, 1959). Indeed, one can view the lifespan of human beings as one of learning how to achieve primary control throughout youth and adulthood as one is faced with the tasks of life, but also of learning secondary coping mechanisms to use when primary control fails (Heckhausen and Schulz, 1995).

Considerable work has been done to articulate the functioning of both primary and second- ary control strategies in situations and across the life-span (e.g., Heckhausen, 1991; Heckhausen and Schulz, 1995). While it is not possible here to delineate the rich set of theoretical propositions developed in this literature, a short summary of some relevant points can inform our hypotheses.

Secondary control can be functional in the larger sense of supporting primary control strategies in other situations. Thus, when faced with an unjust charge on a bill and no apparent way to remove it, an individual might turn to sympathetic friends to receive assurances that he is in the right and did all that he could; thus, his willingness to exercise primary control strategies is maintained in other situations. Or, secondary control strategies can be ultimately dysfunctional to the individual by causing the individual to make attributions of her own personal incompetence when primary control strategies fail, and therefore to become passive in situations where primary control might work. Learned helplessness is a form of dysfunctional secondary control.

Secondary control strategies fall under three major types (Heckhausen and Schulz, 1995): (a) expectation biases, (b) shifts in goal valuation, and (c) biased attributions of outcomes. Which types will be used is very much a function of the individual and the situation. In all cases, however, the individual has given up on obtaining satisfaction from the firm of the sort that they originally expected.

Expectation biases allow the individual to maintain self esteem through altering and justifying his or her perceptions of the likelihood of success. For example, one can justify not trying primary control strategies, such as complaining, by claiming to oneself that such strategies are so unlikely to work that they are not worth the time ("defensive pessimism"). Or, one can adjust the aspiration level ("I think I'll just have to be satisfied with what I have"), or perhaps one will find a congenial group that will confirm that success is infeasible ("no one ever gets that insurance plan to pay for those medications, we've all tried"). In this way, the individual can avoid more threats to his or her self-esteem. 
Goal value shifts allow the individual to devalue to original goal, and/or change goals. For example, "Even if the store had honored that out-of-date discount coupon, I bet those grapes would have been sour by now. I'll find something else I'll like." Or, one can disengage, emotionally, from the original goal: "I expected the insurance company to return my car to its original appearance, but heck, it's an old car, so who cares?" Additionally, one can make the original goal subordinate to other goals and thus justify not achieving it: "I'm going to just ignore the fact that the cable TV company forces me to pay for the sports channel, and learn to enjoy watching sports," or " I'm going to just sit back and wait for an opportunity for revenge," or "I'm going to tell all my friends how manipulative and exploitative this company is and hope the company loses business."

Finally, one can bias attributions of outcomes. That is, in order to support one's sense of personal agency or power, one can attribute malevolence, incompetence, or overwhelming power to the firm, thus maintaining one's moral high ground as a victim: "They were big, dirty fighters/they've stacked the cards in their favor/they can't even understand their own policies." One can attribute heroic motives to oneself: "I fought the good fight knowing I would probably lose to these malevolents/incompetents, but I think they knew they were in a fight." By using such attributions, one can maintain a view of oneself as capable of winning the day in a fair fight, just not an unfair one perpetrated by an unfair opponent.

According to Hirschman (1970), customers will do nothing when service failure occurs and exit barriers are very high. However, instead of assuming that customers "do nothing" when exit and voice are both too costly, secondary control theory asserts that customers, in fact, "do something." The coping behavior of the customers is more subtle because they are not focused on changing the environment, but instead are focused on changing the self to adjust to the environment (Skinner, 1996) by changing self-perceptions, goals and priorities, or expectancies for outcomes. Although customers "do nothing" as far as the firm may be able to tell, we will show that secondary control, as customer's means of coping with powerlessness, may have serious consequences to the firm.

\section{Hypothesis development}

\section{Manipulating powerlessness}

In this research, we use scenario-based methods to systematically vary the amount of powerlessness customers feel. Scenarios were used to help control for variability of the exit barriers and level of service failure, and have been used in previous research to control for other servicerelated variables (Huppertz, 2007). The scenarios either had a high- or low-exit barrier and a good or poor service recovery; these conditions were shown to cause variation in powerlessness. Later, we hypothesize how the three measures of secondary control are related as the consequences of powerlessness.

\section{Exit barriers}

An exit barrier is a condition of a relationship under which a customer perceives a cost or a loss will occur if he or she exits the relationship. Exit barriers are also referred to as switching costs, and are conceptualized into three different types: procedural, financial, and relational (Burnham et al., 2003). A fourth exit barrier category is structural, and occurs when consumers do not believe there is realistically an exit option (Andreasen, 1985).

A procedural exit barrier or switching cost is one in which the customer is required to expend money, time, risk, or effort to switch to a new supplier. For example, finding a new doctor may involve time expenditure to speak to friends, plus the risk of finding a doctor that delivers poorer service than the current one. A financial exit barrier is one in which the customer loses financially by switching, as many customers do when switching out of mobile telephone plans prior to the contract expiration (due to penalty fees). A relational 
exit barrier is one in which the customer loses relationship bonds or the identity benefits of such bonds; for example, switching away from a country club, commercial gym, or high-status supplier can involve such costs.

A structural exit barrier is characterized as a condition in which customers may not believe that there is an exit option because of a lack of actual competition within an industry (for example, public schools), or because the customer lacks knowledge regarding exiting options (for example, prescription drugs, when equally effective generics are available but not prescribed). Hirschman (1970) refers to this exit barrier condition as "loose monopolies." Fournier (1998, p. 362) refers to this exit barrier condition, somewhat dramatically, as "enslavement" and defines it as a "non-voluntary union governed entirely by desires of the relationship partner." This relationship "involves negative feelings but persists because of circumstances." It should be true that customers will naturally feel somewhat powerless in a relationship with high structural exit barriers, in which their money or time will be taken from them whether they wish to exit or not. We manipulate structural exit barriers in this research, to achieve the maximum effect on powerlessness.

\section{Service failures in customer-firm relationships}

In this work, we have also used service failures to manipulate powerlessness. Product failures can also manipulate powerlessness, but service failures are a more reliable context for producing powerlessness since service contexts can easily imply the existence of a relationship of some duration and can also easily accommodate highor low-exit barriers. Examples of service failures in long-duration relationships with high-exit barriers would be a serious misdiagnosis by a longtime family doctor or a terrible haircut by a regular women's beautician. A similar case, but with low-exit barriers, would be a bad haircut by a regular men's barber for a customer who is nearly bald, when any other barber will probably be just as competent or better.
Bitner et al. (2000) define service failure as "decreasing quality in what has been termed the 'service encounter'." In this research, we investigate the case in which the service failure and the quality of recovery are under the company's control, and yet (in one condition of the experiment), recovery is nonetheless poor. If customers attribute service failures to controllable factors, they may become even more dissatisfied toward that company, and feel powerless, at least temporarily (Kelley et al., 1993). Service quality, because of the usual complexity of services and the many variables involved, is almost certain to decline at least temporarily at some point and generate a service failure (Smith et al., 1999). Service failures under conditions of high-exit barriers will force the customer to face his or her powerlessness. Additionally, if a firm responds to a service failure with poor service recovery efforts, customer's negative feelings toward that firm may intensity, thus producing a "double deviation" effect (Bitner et al., 1990; Maxham and Netemeyer, 2002).

\section{Consequences of powerlessness: \\ Grudge-holding, predictive avoidance, and retaliation desire}

As discussed earlier, powerless customers are likely to engage in secondary control. Because there were so many possible forms of secondary control (see the discussion under "secondary control"), we conducted a qualitative study to assess the most likely types.

In the qualitative study, we interviewed 28 people using in-depth and structured interviews, opening with questions like, "Have you ever had a service failure with a company in which you felt it would be difficult to switch?" Subjects rarely had difficulty remembering voluminous detail of such situations; in fact, we were approached by people who heard we were conducting the study and wanted to tell their stories, which is certainly an indication of secondary coping. Most interviews lasted at least 30 minutes and the longest lasted 90 minutes, and 
concerned our informants' relationships with organizations as diverse as utilities, health maintenance organizations, large banks, apartment complexes, government agencies and services, telecommunications, etc.

It was clear to us that virtually all of the subjects were still carrying a grudge even if the incident was a decade before and they were still customers of the company. Many showed visible signs of anger during the interviews. So, it was clear to us that one type of secondary coping that should be measured and tested was grudge-holding.

In addition, it was very common for subjects to mention cutting off communication with the company either out of frustration or out of fear of retaliation. In other words, further attempts at primary control were predicted to be either useless or counter-productive; this is one form of avoidance as discussed below. Finally, most informants not only harbored a grudge but wished they could retaliate against the firm, although none admitted to doing so. However, they did admit to fantasizing about revenge on occasion. This is called retaliation desire.

\section{The sequence of events in secondary control}

Control strategies follow phases (Heckhausen, 1991; Heckhausen and Schulz, 1995), which will inform our hypotheses regarding which of the secondary coping mechanisms are likely prior to others. In the use of any control strategy, there is first a pre-decisional phase. Secondary control strategies that anticipate failure of primary control and result in avoidance of primary control strategies ("well, this probably isn't going to work, given my temper," or "I'm not even going to try") are examples of what occurs in this phase. In the preactional volition phase, one develops plans and motivates oneself to complete the strategy. In terms of secondary control, one might develop a strong desire for revenge against the firm that is exploiting one, for example. In the actional volition phase, one executes the strategy. Finally, in the postactional motivation phase, one attributes causality and develops beliefs about what one has learned from the results (if functionally, usually in a way that maintains self-esteem and motivation for primary control). A secondary control strategy for the postactional phase might be one in which a customer imagines plans for future action if one finds oneself in the same situation in the future.

The likely sequence of secondary control strategies can help establish which secondary control strategies may be logically hypothesized to be antecedent to other secondary control strategies, as we propose below under hypothesis development. Essentially, we will propose that recognition of one's powerlessness may lead to both grudge-holding and predictive avoidance; further, we will propose that grudge-holding, in addition, leads to both predictive avoidance and retaliation desire.

\section{Grudge-holding}

Grudge-holding is defined as a condition under which people maintain a victim role and perpetuate negative emotions associated with rehearsing the hurtful offense (Witvliet et al., 2001). Nursing a grudge is associated with a commitment to remain angry about a particular offense (Witvliet et al., 2001). A benefit of holding a grudge toward a perpetrator of a wrongdoing is that it provides the victim a moral high ground by virtue of having been wronged (Exline and Baumeister, 2000). For example, a customer who holds a grudge against a stock broker for over-investing his portfolio in stocks prior to a stock market crash may have several benefits to nurturing a victim role. He can avoid his own responsibility, if any. He can justify the effort required to switch brokers. He can justify his own moral superiority by rationalizing that the broker was motivated by overweening greed while he is not.

In order to adjust to feelings of powerlessness, people label themselves as victims, thus justifying "ongoing feelings of anger and righteous indignation-emotions that can make them feel more pow- 
erful"' (Exline and Baumeister, 2000, p. 147). Playing a victim role also occurs in marketing, as one of the characteristics of grudge holders is that they consider whatever went wrong to be all the seller's fault and not at all their own fault (Hunt et al., 1988). Grudge-holding is an example of the type of secondary control called "biasing attributions of outcomes." In order to maintain one's self-esteem, one attributes malevolent motives to the firm.

Grudge-holding, we argue, is likely to occur in the pre-actional volition phase of secondary control. That is, as one realizes that one has been taken advantage of and has no acceptable exit, one becomes angry. Anger is the motivator. One could, of course, shut off anger in the pre-decisional phase by recognizing that one is powerless; but this seems to be difficult for most humans. Thus, grudge-holding, occurring early in the process of secondary control and providing motivations for other strategies, should result directly from powerlessness, and also precede other secondary control strategies.

H1: There is a positive relationship between powerlessness and grudge-holding.

\section{Predictive avoidance}

Predictive avoidance is the extent to which people attempt to predict and avoid negative events so as to avoid disappointment Rothbaum et al. (1982) developed a concept "predictive avoidance" that explains situations in which people who believe they have limited ability and have passive behavior avoid tasks in which the risk of failure is high. This paper looks at a narrower aspect of this construct, which is avoidance of negative events and refers to this aspect as predictive avoidance. For example, a customer who has had the frequent experience of marching all over a certain mega-home-improvement center without finding her desired item may simply switch to a smaller hardware store. So, exit is one example of predictive avoidance. In our research, however, we needed a form of predictive avoidance that would exist under conditions of high structural exit barriers (i.e., the only place in town), and so the form of predictive avoidance we chose to operationalize was communication avoidance. When customers practice this form of predictive avoidance, they are not communicating with the company when a service failure occurs as they believe such communication would only result in more frustration and disappointment.

Predictive avoidance could seem to come at either of two phases of control: the pre- decisional phase or the actional volition phase. One could argue first that recognition of powerlessness could lead directly to avoidance; one decides not to complain any longer because it is pointless. This is an "expectation bias" form of secondary control, and should logically be a direct result of being faced with irrevocable evidence of one's powerlessness.

H2: There is a positive relationship between powerlessness and predictive avoidance.

However, one might also argue that predictive avoidance is a consequence of grudge- holding. That is, grudge-holding is the motivation for an action, which is to cut off communication with the company. The "action" in this case is to do nothing, but as we have argued, that is, in fact, doing something. Predictive avoidance can thus also be a "goal value shift" form of secondary control. One can shift one's goal from altering the situation to maintaining distance from it.

In the marketing literature, grudge-holding has been associated with customers removing themselves from any possible marketing communications with the offending firm, due to strong negative emotional feelings, and with the purposeful commitment of avoiding that firm in the future (Aron, 2001; Huefner and Hunt, 1992).

H3: There is a positive relationship between grudge-holding and predictive avoidance. 


\section{Retaliation desire}

When harm occurs, whether it is caused by a more powerful party or a less powerful party, anger is generally the result (Allred, 2000). The danger of anger within a conflict is that the desire for retaliation may increase thus leading to an actual escalation of the conflict (Allred, 2000). This desire for vengeance is equally true for the less powerful as well as for the more powerful parties involved in the conflict.

The desire for vengeance, but not the actual carry-through, is referred to as retaliation desire. Bougie et al. (2003), in a content analysis of opencoded questions exploring feelings, thoughts, action tendencies, actions, and "emotivational goals" after a negative service incident, found such things as desires for revenge, tendencies toward aggressive actions, and desires to harm the firm or someone at the firm. Retaliation desire is a safe route for the less powerful as they react to harm by resorting to revenge fantasy (Heider, 1958; Bies and Tripp, 1996). For example, a customer may wish that the offending company will experience bankruptcy or become entangled in a messy scandal. Revenge fantasies, or retaliation desires, are not just intrapsychic phenomena, but shared with coworkers and friends as well (Bies and Tripp, 1996), thus adding texture to negative word of mouth behavior, which is another "goal value shift" form of secondary control. Negative word of mouth may result in a negative image and reduced sales for the firm, and is compounded by the fact that consumers seem to place more weight on negative information in making evaluations (Richins, 1983).

There is, logically, a strong connection between grudge-holding and retaliation desire. Grudges are usually held by people angry at an individual or firm, committed to remain angry (Witvliet et al., 2001), and who may entertain thoughts of violence toward the company (Bougie et al., 2003). But, people generally do not carry through with their thoughts of violence because violent action is against their best interests (Aquino et al., 2001), and so retaliation action is replaced by retaliation desire. Grudge-holding is the motivation for retaliation desire, which should logically be at the ac- tional volition stage. Holding a desire to retaliate is a secondary control "action," consequential to grudge-holding, just as predictive avoidance can be.

H4: There is a positive relationship between grudge-holding and retaliation desire.

\section{Methodology}

Sample

Adults were recruited by four community groups (a women's group, a group of Boy Scout parents, and two parochial school groups), and then each group was paid $\$ 5.00$ per adult volunteer that participated in the study. The community groups willingly participated, since this research served as a fundraiser. Out of 326 questionnaires that were turned in, 320 were useable. Demographic characteristics of the subjects were a rough fit to the US population. The sample is a little higher in the proportion of women, a little lower in income, and somewhat lower in the proportions of middle-aged adults than the US population. However, no group is poorly represented. Due to the homogeneous nature of race in this particular region of the United States, race was not measured. In addition, checks to determine if the results vary by age, sex, and income were done (discussed later), and showed little or no difference in the effects of powerlessness by these demographic variables.

\section{Varying powerlessness}

A scenario-based procedure was performed by presenting one of the four scenarios to each of the 320 respondents, approximately 80 per scenario, randomly assigned. Scenario-based experiments are useful for controlling variables that could affect customers' feelings of powerlessness (Rucker and Galinsky, 2008). Powerlessness was tested by controlling the extent of the exit barriers (high vs. low) and the extent of the service recovery (good 
vs. poor). Using scenarios in this context is justified because it manipulates the research service attributes that are important to the purpose of this study (Garry, 2007). The scenarios instructed each subject to imagine that he or she had just moved to a new town and signed up for local telephone service with a local service provider. In two of the scenarios, telephone service was in a competitive market (the low-exit barrier conditions), in which the consumer could easily choose another local provider or a cellular phone provider. In the other two scenarios (the high-exit barrier conditions), there was no cellular phone provider nor any other types of competitor, thus making the local landline telephone company the only source of local telephone service. The scenarios are provided in Appendix A.

Each of the scenarios featured a severe and long-term failure in telephone service. The scenarios then described the company's recovery from this failure in one of two ways. One of the scenarios in each exit barrier condition described the telephone company executing a good recovery from the service failure. The other scenario in each exit barrier condition described a very poor recovery from the service failure. The good service recovery scenarios for this research included the four attributes suggested by Smith et al. (1999): compensation, response speed, apology, and recovery initiation.

The condition of one landline provider and no cellular service was realistic at the time and place the research was conducted (rural Minnesota, 2001), where these conditions often existed. Furthermore, the service failure built into each scenario (repeatedly dropped calls) was realistic in that time and place, where rural land-line and cellular service (where it existed) were both prone to dropped calls due to distance between cell towers, network difficulties, snowstorms, high winds, wet ground conditions, lack of fiber-optic lines, construction, faulty wiring in older homes, and so forth. A pre-test confirmed that the four scenarios produced the expected strong variations in the independent variables.

Powerlessness was measured with three items as shown in Table 1. The powerlessness scale was originally a compilation of seven items.

Table 1. Construct items

Powerlessness $\alpha=0.789$

This telephone company can afford to treat customers poorly, because their customers may believe that they don't have any option but to stay (P1)

This situation would make it feel like I am stuck with no place to go for better telephone service (P2)

It's these types of situations that make me feel trapped with a service provider (P3)

Grudge $\alpha=0.889$

I would harbor a grudge against this telephone company (G1)

If this firm ever came to mind, I would probably remember their treatment of me with some bitterness (G2)

It would be difficult for me to forget the problem I had with this company (G3)

I would think poorly of this telephone company for a long time (G4)

It would be difficult to forgive this company for treating me this way (G5)

Retaliation desire $\alpha=0.831$

If I thought I could get away with it, I'd find some way to pay this company back for what they did to me (RD1)

I could think of ways to get back at this company (RD2)

It would frustrate me to think that I could not get back at this company even if I wanted to (RD3)

Predictive avoidance items $\alpha=0.827$

I would put off complaining to the company if this problem happened again (PC1)

If I encountered another problem with this company, I would procrastinate calling them until I absolutely had to (PC2)

If I started missing conversations again in the future, I would not call this telephone company for help, as that would only frustrate me further (PC3) 
Three of those items were adapted from Pruden et al. (1974), which measured general powerlessness, and four items were created by the authors to measure consumers' expression of powerlessness to switch when dissatisfied after a service failure. A factor analysis was used to purify the items and the three powerlessness items used in this study were closely associated with the inability to switch due to high-exit barriers, thus capturing the "trapped" factor of powerlessness. As presented in Table 2, manipulation checks showed that powerlessness was successfully varied as expected by the exit barrier and quality of service recovery manipulations.

\section{Measurements of the consequences of powerlessness}

Grudge-holding, predictive avoidance, and retaliation desire were measured using multiple items on a seven-point Likert scale, and are shown in Table 1, along with the Cronbach's a score used to assess scale reliability.

The grudge items were adapted from the Wade's forgiveness scale (Wade-Brown et al., 2001). The retaliation desire and predictive avoidance items were adapted from the transgression-related interpersonal motivations inventory (McCullough et al., 1998). All three of these scales were changed to match the situations outlined in the scenarios.

Extensive item analysis was done to reach these items from a larger pool of proposed items. Changes in Cronbach's $\alpha$, item-total correlations, and exploratory factor analyses were used in ini-

Table 2. Means of powerlessness by barrier and recovery conditions

\begin{tabular}{lccc}
\hline \multirow{2}{l}{$\begin{array}{l}\text { Powerlessness } \\
\text { Recovery }\end{array}$} & \multicolumn{2}{l}{ Exit barrier } & \\
\cline { 2 - 3 } quality & Low & High & Main effect \\
\hline Poor & 3.74 & 5.03 & 4.39 \\
& $(n=76)$ & $(n=77)$ & $(n=153)$ \\
Good & 3.09 & 4.60 & 3.87 \\
& $(n=80)$ & $(n=87)$ & $(n=167)$ \\
Main effect & 3.41 & 4.80 & 4.12 \\
& $(n=156)$ & $(n=164)$ & $(n=320)$ \\
\hline
\end{tabular}

tial steps to remove items that were not useful to the four scales. A confirmatory factor analysis on the final items of all four measures showed no cross-loadings among the factors. Tests for discriminant validity following Anderson and Gerbing (1988) and Fornell and Larcker (1981) showed all measures discriminable from each other, and Fornell and Larcker's test of convergent validity showed all measures as possessing convergent validity.

\section{Results}

Consequences of powerlessness

To test hypotheses 1-4, a structural equation model was run using EQS 6.1. The results of the structural equation model are shown in Figure $\mathbf{1}$. The goodness of fit was adequate $\left(\chi^{2}=195.6\right.$, df $=73, \mathrm{CFI}=0.944$, and RMSEA $=0.073$ ). Hypotheses 1-4 were verified with an alpha level of 0.01 . As hypothesized, powerlessness is directly related to grudge-holding and predictive avoidance, and grudge-holding is further related to predictive avoidance and retaliation desire. This gives some insight into the dynamics of powerlessness in customer relationships. By definition powerlessness obviates primary control (Seeman, 1959), and

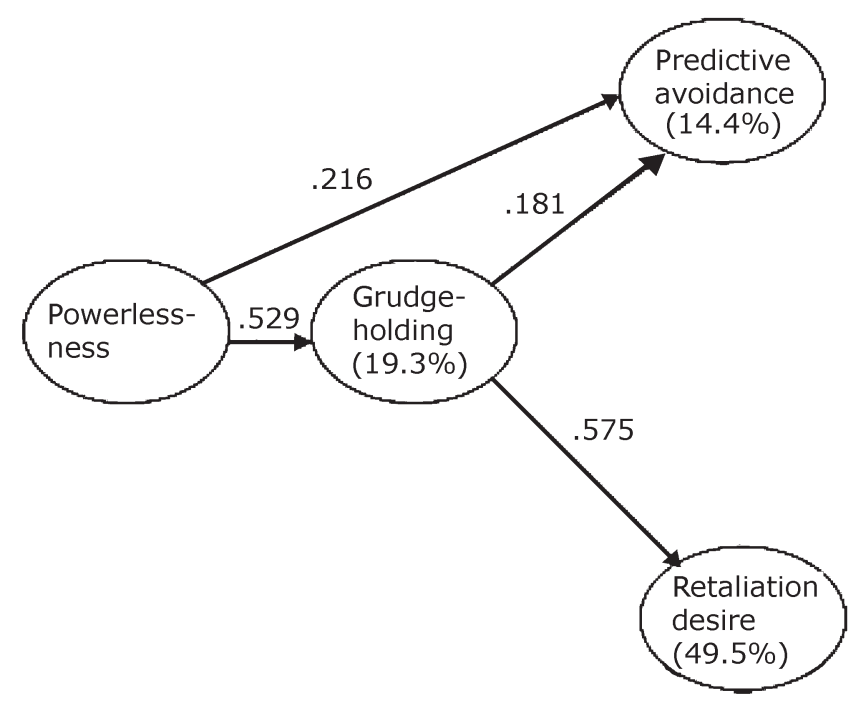

Figure 1. Structural equation model showing the significant paths of Hypotheses 4-8. All paths were significant at $p<.01$. 
pushes customers into the pre-decisional and preactional volition phases of secondary control. Hence, they decide further communication is worthless (Hypothesis 2), but are motivated to hold grudge as means of retaining a sense of control in general (Hypothesis 1).

Tests were performed to determine if the model varied by sex, age, or income. For example, the sample was bifurcated as evenly as possible on the income category and multiple-population structural model was created, to determine if allowing the structural model to vary by income (or sex or age) allowed significantly better fit.

There were no differences between men and women, nor differences between lower- and higher-income groups. There is a difference in the model between younger (less than 36) and older (36 or older) customers.

For the younger group, grudge-holding is related to predictive avoidance, but powerlessness is not. In the older group, the reverse is true. Perhaps this effect is due to more emotional decisionmaking on the part of younger customers: feeling powerless does not cause the customer to withhold communication, but holding a grudge does. For older customers, recognition of powerlessness may cause them to rationally refuse to invest in further communication, while their past experiences may suggest to them that withholding communication is a less effective way of dealing with a grudge, as might be inferred from Heckhausen and Schulz (1995).

\section{Discussion}

This experiment showed that powerlessness varies as one might expect. The feeling of being "trapped" seems to occur most strongly when exit barriers are high, but the feelings of powerlessness are increased when a service failure occurs and recovery is poor. From the point of view of short-term profitability, a firm with a monopoly that provides poor service may indeed do quite well financially. In fact, if the monopoly is rock-solid, such as some government services, and saving money on service is of primary concern, the powerlessness of the consumer may be viewed as a desirable thing by those on the inside of the organization. However, our results argue that the long-term consequences for most organizations of having frustrated, powerless customers will be negative.

It is well understood in the services marketing literature that only a small percentage of dissatisfied customers complains (e.g., Tax and Brown, 1998; Voorhees and Brady, 2005). We would also expect that those holding a grudge would seldom make themselves known. Grudge-holding provokes bitter silences, avoidance, back-stabbing, negative word of mouth, deliberate inefficiency, sabotage, and other passive-aggressive behaviors or retaliations (Hunt et al., 1988). For example, Sprint Telecommunications, in the summer of 2007, ejected about 1000 customers from its service for using up large amounts of customer service time complaining about issues it considered resolved. While many of these customers may have said that their hundreds of calls per month (Washington Post, 2007) were legitimate, probably many of the customers were simply retaliating for what they perceived to be their situation - being trapped in a poor service relationship.

A large negative consequence of grudge-holding is retaliation desire. Although not tested in this research, retaliation desire will probably transform into actual retaliation for a small percentage of customers. They may engage in small passive/ aggressive acts such as paying a late fee in pennies or calling customer service with time-wasting queries. There is always the possibility of more serious acts of vandalism. There are no statistics available on the extent of such retaliatory acts; such acts are often covert, in any case, and overt acts, such as vandalism, can be the result of several motivations. Nonetheless, we believe that retaliatory acts may be substantial and definitely worth the effort to avoid.

Another consequence of powerlessness, predictive avoidance, may also have long-term consequences for marketers. Our results suggest strong links between powerlessness, grudge-holding, and predictive avoidance. So, customers practic- 
ing predictive avoidance will not complain when future service failures occur, nor might they be likely to cooperate with customer satisfaction questionnaires. As a result, the offending company may overestimate the satisfaction of their customers, and when alternatives enter the market, may be surprised by mass exiting behavior by the customers (Jones and Sasser, 1995). It may be difficult for managers to detect psychological responses such as powerlessness, grudge- holding, retaliation desire, and predictive avoidance. But managers and customer-interfacing personnel should be trained to look for signs that reveal customers' extreme dissatisfaction and feelings of powerlessness, and should make an effort to correct their behavior when these signs are evident. As one customer said in an interview about powerlessness, "I have to give it all to them cause I'm just a peon in the world who wants their little service, and if I want their little service then I've got to prove to them that I paid their bill, regardless of whether they screwed me over or not. It kind of frustrates me."

So, for practicing managers, failure to detect feelings of powerlessness and their consequent grudge-holding, predictive avoidance, and retaliation desires, may have the following effects:

1. If a significant fraction of the customer base feels powerless, then massive and unexpected defections may occur if competition becomes viable. If a significant fraction of the customer base is holding a grudge, negative word-of-mouth may significantly lower the public image of the company without an apparent reason.

2. If a significant fraction of the customer base is exercising predictive avoidance due to powerlessness and grudge-holding, managers will not learn about the unhappiness unless some large negative effect on the business causes them to suspect and investigate.

3. If a significant fraction of the customer base is feeling retaliation desires, management may be unaware until those desires are manifested in actual retaliation, such as large costs in customer service to a small number of customers, or some other negative financial consequence, occur and are detected.

What do managers need to do to cope with the powerlessness of their own customers? First, managers need to be aware of the extent to which their customers are, in fact, trapped. This should be obvious to most managers. Utilities, small stores in isolated towns, public schools, and company-plan health insurers are frequently structural monopolies. Other businesses, such as airlines, have the customer in their power once a ticket is purchased or a flight initiated, or a loyalty program is joined.

The existence of such situations should make managers more diligent in preventing service failures, more diligent in recovering well from service failures, and more willing to develop strategies to return power to the customer without harming the firm in the long run. For example, an airline that must cancel flights can offer free access to a lounge, alternative flights to nearby cities, flights on other airlines to the destination city, and/ or train service employees to recognize circumstances likely to provoke grudges. Customer satisfaction surveys can include questions designed to detect the level of grudge-holding and the reasons for it. For customers who are financially valuable, open communication about the reasons for apparent service failures and dialogue regarding how such failures can be dealt with to the satisfaction of the customer may be valuable. Expanding the number of touch-points and the ease of accessing them using web sites and other forms of information technology (Bitner et al., 2000) may encourage complaints and help to defuse grudge-holding and other consequences. For customers whose behavior in response to powerlessness and grudgeholding pushes them into negative value with the firm, a resolution to end the relationship may be in order.

\section{Limitations}

Scenario-based experiments are limited by the fact that scenarios, while realistic, are not real and people may not relate to them in exactly the 
same way that they would to a real-life situation. Future research can investigate these same constructs using different methodologies (questionnaire, observation at a complaint desk, etc.). While these results, based on broad concepts, seem to us to be likely to be robust beyond the telephone service market, they may not generalize to all situations. For example, in a marketplace such as government services in a corrupt society, it is possible that many customers of those services may be unable to conceive of receiving good service or being able to exit the government services. If so, powerlessness may be viewed as simply a fact of life, and no grudges may be held. However, we would still expect predictive avoidance. So, largely, we think the model is likely to hold up well in service relationships in most cases.

\section{Future directions}

Although powerlessness seems to occur as a result of a service failure with a company that has high-exit barriers, it may have other antecedents as well. Future research can explore the antecedents of powerlessness and determine what types of situations tend to contribute to feelings of powerlessness. There might be consequences, other than the three investigated here, that are costly to the firm as well. Finally, it is important to understand the extent to which and under what conditions retaliation desire becomes actual retaliation, in the form of costly and/or dangerous acts by customers.

\section{The Authors}

Matthew P. Bunker, Ph.D, is an Associate Professor at the University of Northern Iowa, USA. His teaching interests are marketing research, services marketing and interactive marketing. Dr. Bunker's research emphasizes customer service, service failure and recovery and interactive marketing. He has published in Advances in Consumer Research, the Journal of Services Marketing, the Journal of Consumer Satisfaction, Dissatisfaction, and Complaining Behavior, the International Journal of Consumer Studies, and the International Journal of Business Information Systems.
Dr. A. Dwayne Ball, Associate Professor of Marketing at the University of Nebraska- Lincoln, received his Ph.D. from Ohio State University, has been a consumer research manager for the Procter and Gamble Company, a visiting faculty member at the University of Canterbury in New Zealand, and a recipient of two Fulbright Awards to teach and do research at the Higher Institute for Statistics and Information Management in Lisbon, Portugal. Dr. Ball has published in the Journal of Marketing Research, the Journal of Business Research, the Journal of Consumer Psychology, the European Journal of Marketing, and many others. He is an associate editor of the Journal of Services Marketing. Dr. Ball's current research interests are in understanding customer loyalty, statistical methods used in the analysis of large consumer databases, measurement of consumer behavior constructs, and academic freedom.

\section{References}

Allred KG. 2000. Anger and retaliation in conflict. In The Handbook of Conflict Resolution, Morton D, Peter TC (eds.). Jossey-Bass: San Francisco, CA; 236-255.

Anderson JC, Gerbing DW. 1988. Structural equation modeling in practice: a review and recommended two-step approach. Psychological Bulletin 103: 411-423.

Andreasen AR. 1985. Consumer responses to dissatisfaction in loose monopolies. Journal of Consumer Research 12: 135-141.

Aquino K, Tripp TM, Bies RJ. 2001. How employees respond to personal offense: the effects of blame, attribution, victim status, and offender status on revenge and reconciliation in the workplace. Journal of Applied Psychology 86(1): 52-59.

Aron D. 2001. Consumer grudgeholding: toward a conceptual model and research agenda. Journal of Consumer Satisfaction, Dissatisfaction, and Complaining Behavior 14: 108-119.

Baker SM, Gentry JW, Rittenburg TL. 2005. Building understanding of the domain of consumer vulnerability. Journal of Macromarketing 25(2): 128-139.

Bandura, Albert. 1986. Social Foundations of Thought and Action: A Social Cognitive Theory. PrenticeHall: Englewood Cliffs, NJ.

Bies RJ, Tripp TM. 1996. Beyond distrust: 'getting even' and the need for revenge. In Trust in Organizations: Frontiers of Theory and Research, Kramer 
RM, Tyler TR (eds.). Sage: Thousand Oaks, CA; 246-260.

Bitner MJ, Booms BH, Tetreault MS. 1990. The service encounter: diagnosing favorable and unfavorable incidents. Journal of Marketing 54(1): 71-84.

Bitner MJ, Brown SW, Meuter M. 2000. Technology infusion in service encounters. Journal of the Academy of Marketing Science 28(1): 138-149.

Bougie R, Pieters R, Zeelenberg M. 2003. Angry customers don't come back, they get back: the experience and behavioral implications of anger and dissatisfaction in services. Journal of the Academy of Marketing Science 31(4): 377-393.

Burnham TA, Frels JK, Mahajan V. 2003. Consumer switching costs: a typology, antecedents, and consequences. Journal of the Academy of Marketing Science 31(2): 109-126.

Exline JJ, Baumeister RF. 2000. Expressing forgiveness and repentance: benefits and barriers. In Forgiveness: Theory, Research, and Practice, McCullough ME, Pargament KI, Thoresen CE (eds.). The Guilford Press: New York, NY; 133-155.

Fiske ST, Morling B, Stevens LE. 1996. Controlling self and others: a theory of anxiety, mental control, and social control. Personality and Social Psychology Bulletin 22(2): 115-123.

Fornell C, Larcker DF. 1981. Evaluating structural equation models with unobservable variables and measurement error. Journal of Marketing Research 18(1): 39-50.

Fournier S. 1998. Consumers and their brands: developing relationship theory in consumer research. Journal of Consumer Research 24(4): 343-373.

Garry T. 2007. An investigation into the mediating influence of consumer expertise on the antecedents and consequences of affect within professional service markets. Journal of Marketing Management 23(5-6): 461-481.

Heckhausen H. 1991. Motivation and Action. Springer: New York.

Heckhausen J, Schulz R. 1995. A life-span theory of control. Psychological Review, 102(2): 284-304.

Heider F. 1958. The Psychology of Interpersonal Relations. John Wiley and Sons: New York, NY.

Hirschman AO. 1970. Exit, Voice, and Loyalty. Harvard University Press: Cambridge, MA. Huefner JC, Hunt HK. 1992. Brand and store avoidance: the behavioral expression of dissatisfaction. Journal of Consumer
Satisfaction, Dissatisfaction and Complaining Behavior 5: 228- 232 .

Huppertz JW. 2007. Firms' complaint handling policies and consumer complaint voicing. Journal of Consumer Marketing, 24(7): 428-437.

Hunt HK, Hunt HD, Hunt TC. 1988. Consumer grudge holding. Journal of Consumer Satisfaction, Dissatisfaction and Complaining Behavior 1: 116-118.

Jones TO, Sasser WE Jr. 1995. Why satisfied customers defect. Harvard Business Review 73(6): 88-99.

Kelley SW, Hoffman KD, Davis MA. 1993. A typology of retail failures and recoveries. Journal of Retailing 69(4): 429-452.

Keltner D, Gruenfeld DH, Anderson C. 2003. Power, approach, and inhibition. Psychological Review 110(2): 265-284.

Maxham JG III, Netemeyer RG. 2002. A longitudinal study of complaining customers' evaluations of multiple service failures and recovery efforts. Journal of Marketing 66(4): 57-71.

McCullough ME, Sandage SJ, Brown SW, Rachal KC, Worthington EL Jr., Hight TL. 1998. Interpersonal forgiving in close relationships: II. Theoretical elaboration and measurement. Journal of Personality and Social Psychology 75(6): 1586-1603.

Mikulincer M. 1994. Human Learned Helplessness: A Coping Perspective. Plenum Press: New York, NY.

Pruden HO, Shuptrine FK, Longman DS. 1974. A measure of alienation from the marketplace. Journal of the Academy of Marketing Science, 2: 610-619.

Richins ML. 1983. Negative word-of-mouth by dissatisfied consumers: a pilot study. Journal of Marketing 47(1): 68-78.

Rothbaum F, Weisz JR, Snyder SS. 1982. Changing the world and changing the self: a two-process model of perceived control. Journal of Personality and Social Psychology 42(1): 5-37.

Rucker DD, Galinsky AD. 2008. Desire to acquire: powerlessness and compensatory consumption. Journal of Consumer Research 35(2): 257-267.

Seeman M. 1959. On the meaning of alienation. American Sociological Review, 24(6): 783- 791.

Seligman MEP. 1975. Helplessness: On Depression, Development, and Death. W. H. Freeman and Company: San Francisco, CA.

Skinner EA. 1996. A guide to constructs of control. Journal of Personality and Social Psychology 71(3): 549-570. 
Smith AK, Bolton RN, Wagner J. 1999. A model of customer satisfaction with service encounters involving failure and recovery. Journal of Marketing Research 36(3): 356-372.

Tax SS, Brown S. 1998. Recovering and learning from service failure. Sloan Management Review 40(1): $75-88$.

Voorhees CM, Brady MK. 2005. A service perspective on the drivers of complaint intentions. Journal of Service Research 8(2): 192-204.

Wade-Brown S, Gorsuch R, Rosik CH, Ridley CR. 2001. The development of a scale to measure forgiveness. Journal of Psychology and Christianity 20(1): 40-52.
Washington Post. 2007. Customer service hangs up. Washington Post, June 7 2007; D-1.

White RW. 1959. Motivation reconsidered: the concept of competence. Psychological Review 66(3): 297-2333.

Witvliet CV, Ludwig TE, Laan KLV. 2001. Granting forgiveness or harboring grudges: implications for emotion, physiology, and health. Psychological Science 12(2): 117-123.

Yi Y, Gong T. 2008. The electronic service quality model: the moderating effect of customer self- efficacy. Psychology and Marketing 25(7): 587- 601.

\section{Appendix: Four scenarios used in the experiment}

Each experiment started out with the set up of the firm in the marketplace. The firm either had no competition, or competition was available. The two different market conditions are shown below. The next step in the experiment described a service failure which was accompanied by either a very good service recovery effort or poor service recovery effort.

\section{Non competitive environment}

You just moved into an area of the country where the only phone service available is provided through one local telephone company. Cellular phone service is not an option available for residents of this area. So, you are limited to a single provider of local telephone service. After finding a place to live, you gather information about this particular telephone provider. Based on the information that you collected about this provider, you contact this local telephone company in order to set up your phone service.

\section{Competitive environment}

You have just moved into an area of the country where three different carriers provide local phone service. There are also several companies that offer cellular phone service as well. After finding a place to live, you gather information about several different providers. Based on the information that you collected about each provider, you contact one of the local telephone companies in order to set up your phone service.

\section{Good service recovery effort}

After 2 months of receiving good service from your local telephone provider, you begin to notice that you cannot hear people talking on the phone, although they can hear you talk. This problem is frustrating and annoying, as it requires that you hang up and call the person back in order to complete your phone conversation. You call the telephone company and tell them the problem; the customer 
service representative tells you that they will send somebody out to look at it. For a few days, you can talk on the phone without any interruptions, but then the same problem starts again. You call the telephone company again, and they tell you the root of this problem lies with the switching equipment in their offices that affects your line, and perhaps a few others.

After 3 months, during which many important phone calls are interrupted, and you repeatedly call the telephone company to complain, the problem is finally fixed. The telephone company is very contrite and apologetic. A service representative calls you several days after the problem was fixed, as well as 2 weeks later, to make sure you are receiving good service. The service representative tells you that the telephone company will give you 3 months of free local service as compensation for the problem. In addition, the representative gives you a special telephone number to call if the problem ever occurs again, where you will receive immediate attention.

\section{Poor service recovery effort}

After 2 months of receiving good service from your local telephone provider, you begin to notice that you cannot hear people talking on the phone, although they can hear you talk. This problem is frustrating and annoying, as it requires that you hang up and call the person back in order to complete your phone conversation. You call the telephone company and tell them the problem; the customer service representative tells you that they will send somebody out to look at it. For a few days, you can talk on the phone without any interruptions, but then the same problem starts again. You call the telephone company again, and the customer service representative tells you the root of this problem lies with the switching equipment in their offices that affects your line, and perhaps a few other lines as well.

After 3 months, during which many important phone calls are interrupted, and you repeatedly call the telephone company to complain, the problem seems to go away. You call the telephone company again to make sure that your service will not cut out again, and they tell you, that they cannot guarantee anything because the problem is with the switching equipment and they really do not plan to replace that equipment any time in the future. The telephone company, however, still sends you full bills for the 3 months of spotty service, refuses to give any type of compensation, and does not apologize. 